\title{
Post cesarean pregnancy and its outcome
}

\section{B. Jeyamani, B. Sowmiya*}

Department of Obstetrics and Gynecology, Vinayaka Mission's Kirupananda Variyar Medical College and Hospitals, Salem, Tamil Nadu, India

Received: 30 September 2021

Accepted: 29 October 2021

\section{*Correspondence:}

Dr. B. Sowmiya,

E-mail: sowmiyab04@gmail.com

Copyright: () the author(s), publisher and licensee Medip Academy. This is an open-access article distributed under the terms of the Creative Commons Attribution Non-Commercial License, which permits unrestricted non-commercial use, distribution, and reproduction in any medium, provided the original work is properly cited.

\section{ABSTRACT}

Background: Though in recent years lower segment cesarian section (LSCS) procedure is the major reason for the reduction in the mortality rate for both mother and baby, inappropriate indications may affect the outcome of pregnancy. Thus, this study was done with the aim of assessing the prevalence of outcome of delivery among women who underwent caesarean section (CS) and to assess the factors associated with that outcome.

Methods: This study was conducted with a sample of 98 pregnant mothers. After acquiring informed consent, those mothers who were indicated for CS (both elective and emergency) were enquired about the questionnaire containing two parts. Part one is about the history regarding previous birth and the next part is about age, parity, and outcome of current pregnancy (both mother and baby).

Results: The mean age of the study participants is 27 years. Among the study participants, about half of them (51\%) were in gravida one and 37 percent have one abortion. About four-fifths of the study participants (81\%) were undergone elective LSCS. About one-fourth of the baby needs neonatal intensive care unit (NICU) admission and two percent have the complication of neonatal sepsis. The factors significantly associated with NICU admission of babies delivered after LSCS are more number of the previous history of abortions ( $\mathrm{p}=0.004)$ and emergency LSCS ( $\mathrm{p}=0.001)$ by $\mathrm{using}$ the chi-square test.

Conclusions: The indication of previous LSCS for LSCS among pregnant mothers is in a rising trend that needs holistic commitment to reduce the prevalence of LSCS.

Keywords: Post cesarean pregnancy, Previous LSCS, Emergency cesarean, Vaginal birth after caesarean, Neonatal sepsis

\section{INTRODUCTION}

In recent years due to many reasons, the prevalence of CS is in increasing trend and the important reasons are found to be patient's preferences, fear of vaginal delivery, and social norms. ${ }^{1}$ The difference in CS rate between private hospitals and government facilities reflects the role of money and income in managing pregnancy. ${ }^{2}$ If there is a medical indication, delivery by CS is a life-saving boon to pregnant women. But CS done with inappropriate indications has severe adverse effects on the outcome of the delivery (for both mother and baby). There is a marked difference between the prevalence of CS in developed and developing countries. A very low CS rate reflects a lack of facility for proper surgical care and a high rate reflects socio-medical factors such as high socioeconomic status, culture, high prevalence of private delivery, and health insurance. ${ }^{3,4}$ As per the WHO report CS rate of more than 10 percent in any country or region has no benefits in reducing mortality in both mother and child. ${ }^{5}$ According to the national family health survey (NFHS 4) the prevalence of CS among pregnant women in India is 17.2 percent. $^{6}$ The prevalence of CS in Tamil Nadu is two times greater than the national average. ${ }^{7}$ With this background this study was done with the aim of assessing the prevalence of outcome of delivery among women who underwent CS and to assess the factors associated with that outcome. 


\section{METHODS}

An observational study was done among pregnant mothers who came to the labor ward for six months from $1^{\text {st }}$ January to $30^{\text {th }}$ June in the year 2021. The ethical clearance was obtained from the ethical committee of Vinayaka Mission's Kirupananda Variyar medical college and hospital, Salem. The sample size was calculated by using the formula $4 \mathrm{pq} / \mathrm{d}^{2}$ where the prevalence of NICU admission after CS as p (as per the study conducted by Seal et al the prevalence is 11 percent $^{8}$ ), and absolute error as $7 \%$. The estimated sample size is 80 . Pregnant mothers with medical complications and previous classical CS s were excluded from the study. After acquiring informed consent, those mothers who were indicated for CS (both elective and emergency) were enquired about the questionnaire containing two parts. Part one is about the history regarding previous birth (any complications and outcome). The second part is about age, parity, and outcome of current pregnancy (both mother and baby). Patients could go for spontaneous delivery after ensuring that there was no obvious feto-pelvic disproportion (Induction was not done). A general, physical, systemic, and obstetric examination was done for all mothers. If the immediate post-natal period for both baby and mother is uneventful then the outcome is termed as good. Other outcomes in our study are the prevalence of NICU admission after LSCS, reasons for NICU admission, and any neonatal complications. The association of risk factors with outcomes was analyzed using the chi-square test (if 20 percent of cells have expected value more than 20 percent Fisher exact test was used). The data were entered in excel and analyzed using SPSS version 21.

\section{RESULTS}

The total number of participants in this study is 98 . The mean age of the study participants is 27 years. The age distribution of the pregnant mothers is shown in Table 1 and Figure 1. Among the study participants, about half of them $(51 \%)$ were in gravida 2 and 37 percent have one abortion. The distribution of gravida and abortion has shown in Figures 2 and 3. There is no maternal and perinatal mortality. About four-fifths of the study participants $(81 \%)$ were undergone elective lower segment CS (LSCS) (Figure 4). About one-fourth of the baby needs NICU admission and two percent have the complication of neonatal sepsis (Figures 5 and 6).

About $60 \%$ of the study participants have posted for LSCS with the indication of previous LSCS and $10 \%$ of participants were indicated for breech and foetal distress (Figure 7). Among the delivered babies about $27 \%$ of babies were admitted to NICU, among them the major reason for admission is respiratory distress syndrome (46 percent) (Table 2). The factors significantly associated with NICU admission of babies delivered after LSCS are more number of the previous history of abortions $(p=0.004)$ and emergency LSCS $(p=0.001)$ by using the chi-square test (Table 3 ).

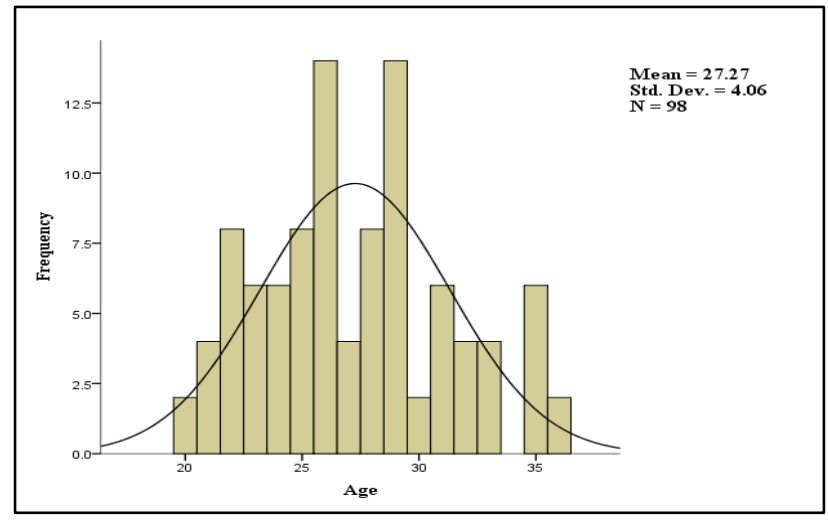

Figure 1: Age distribution of study participants, $(\mathbf{n}=98)$.

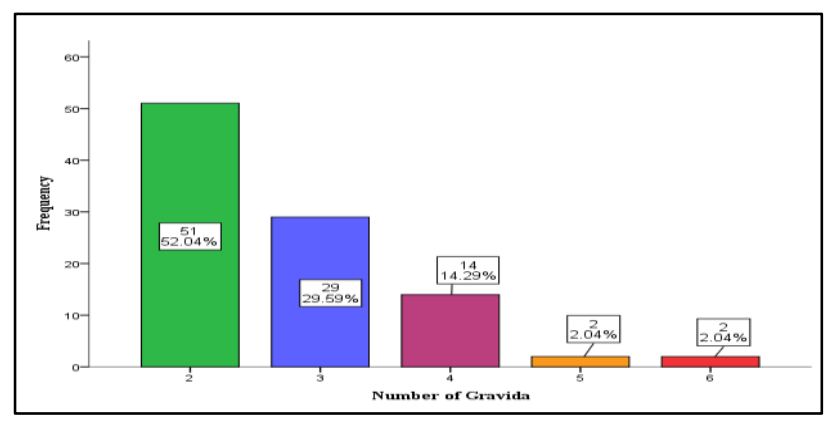

Figure 2: Distribution of study participants according to number of gravida, $(n=98)$.

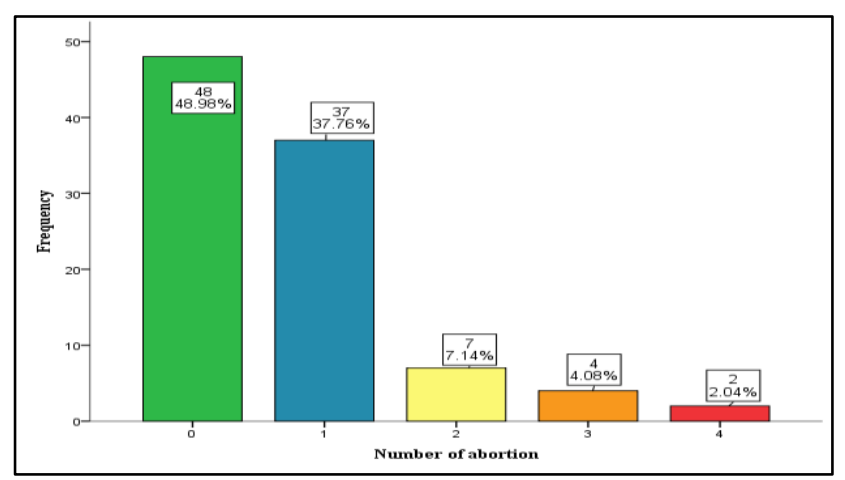

Figure 3: Distribution of study participants according to number of abortions, $(n=98)$.

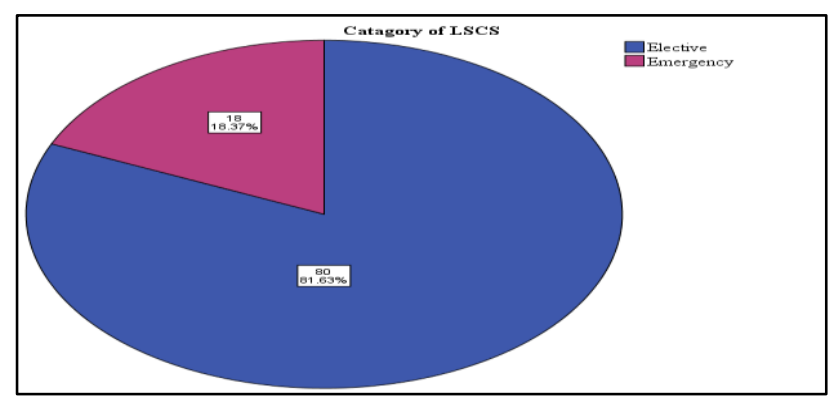

Figure 4: Distribution of categories of LSCS among study participants, $(n=98)$. 


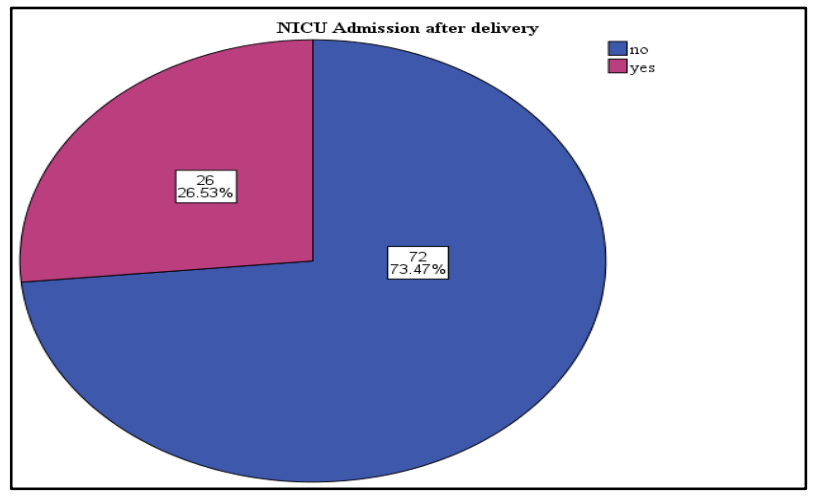

Figure 5: Distribution of NICU admission of baby after LSCS, $(\mathbf{n = 9 8})$.

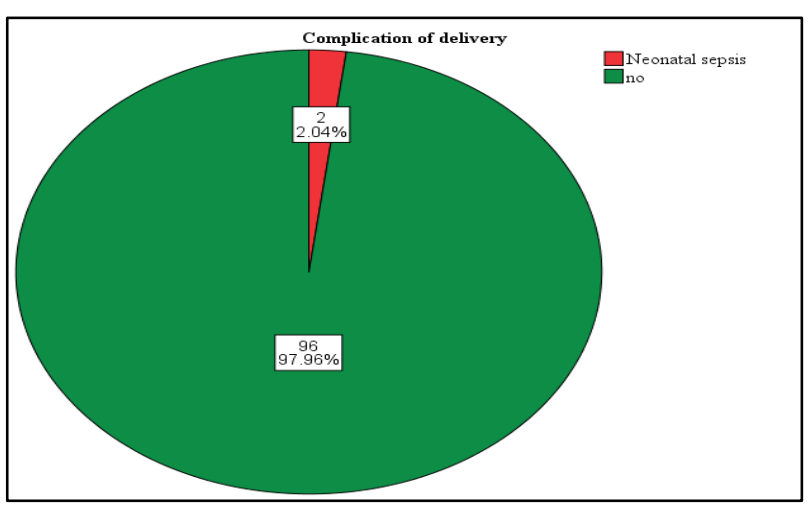

Figure 6: Distribution of delivered babies according to the complication of LSCS, $(n=98)$.
Table 1: Age distribution of study participants, $(n=98)$.

\begin{tabular}{|ll|}
\hline Age $($ Years $)$ & Frequency $(\mathbf{N})$ \\
\hline Mean \pm SD & $27.27 \pm 4.060$ \\
\hline Median $($ IQR) & $27(24.00-29.25)$ \\
\hline Mode & 26 \\
\hline Minimum age & 20 \\
\hline Maximum age & 36 \\
\hline
\end{tabular}

SD-Standard deviation, IQR-Interquartile Range

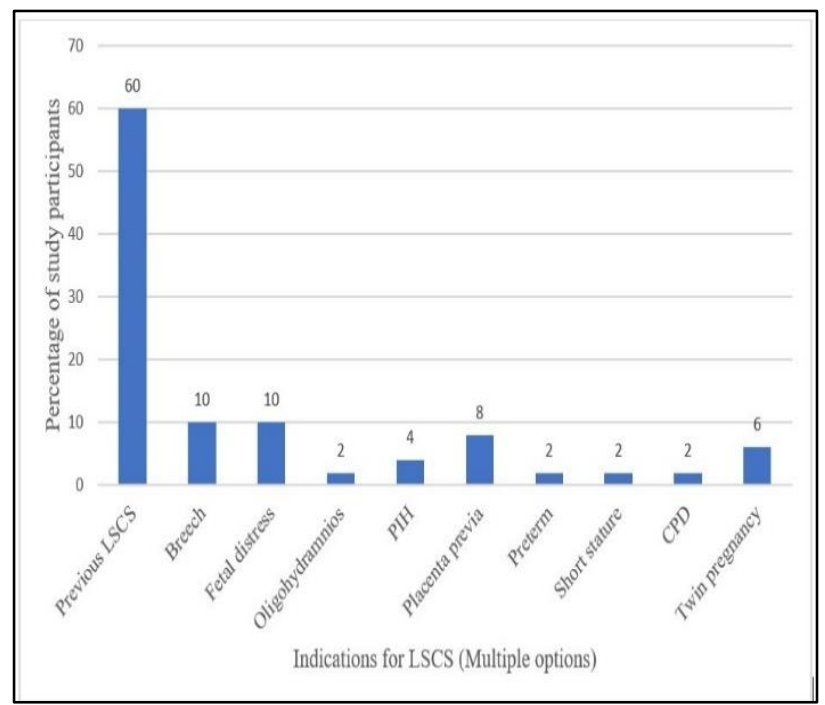

Figure 7: Distribution of delivered babies according to the complication of $\mathrm{LSCS}$, $(\mathrm{n}=98)$.

Table 2: Indications for NICU admission of babies after LSCS, (n=98) (multiple options).

\begin{tabular}{|lll|}
\hline Reason for admission & Frequency $(\mathbf{N})$ & Percentage $(\%)$ \\
\hline Low birth weight & 8 & 30 \\
\hline Meconium aspiration & 2 & 8 \\
\hline Prematurity & 7 & 27 \\
\hline Respiratory distress syndrome & 12 & 46 \\
\hline
\end{tabular}

Table 3: Factors associated with NICU admission, $(\mathrm{n}=98)$.

\begin{tabular}{|c|c|c|c|c|c|}
\hline \multirow{2}{*}{ Variables } & & \multicolumn{2}{|c|}{ NICU admission } & \multirow{2}{*}{$\mathrm{X}^{2}$ value } & \multirow{2}{*}{ P value } \\
\hline & & Yes $(\%)$ & No $(\%)$ & & \\
\hline \multirow{5}{*}{ Gravida } & 2 & $10(19.6)$ & $41(80.4)$ & \multirow{5}{*}{7.033} & \multirow{5}{*}{0.100} \\
\hline & 3 & $10(34.5)$ & $19(65.5)$ & & \\
\hline & 4 & $4(28.6)$ & $10(71.4)$ & & \\
\hline & 5 & $0(0)$ & $2(100)$ & & \\
\hline & 6 & $2(100)$ & $0(0)$ & & \\
\hline \multirow{5}{*}{$\begin{array}{l}\text { Number of } \\
\text { abortions }\end{array}$} & 0 & $6(12.5)$ & $42(87.5)$ & \multirow{5}{*}{13.537} & \multirow{5}{*}{0.004} \\
\hline & 1 & $13(35.1)$ & 24 (64.9) & & \\
\hline & 2 & $3(42.9)$ & $4(57.1)$ & & \\
\hline & 3 & $2(50)$ & $2(50)$ & & \\
\hline & 4 & $2(100)$ & $0(0)$ & & \\
\hline \multirow{2}{*}{ Nature of LSCS } & Elective & $12(15)$ & $68(85)$ & \multirow{2}{*}{26.576} & \multirow{2}{*}{$<0.001$} \\
\hline & Emergency & $14(77.8)$ & $4(22.2)$ & & \\
\hline
\end{tabular}




\section{DISCUSSION}

The mean age of the study population in our study who underwent LSCS is 27 years. A study done by Singal et al in northern India shows the mean age as 23 years. Thus this age difference can influence the outcome of pregnancy which needs further research. ${ }^{9}$ The mother's outcome of pregnancy in our study is $100 \%$ uneventful. A study conducted by Seal et al among 1826 mothers in 2010 were concluded that there are 2 maternal deaths. This could be due to a difference in the sample size. ${ }^{8}$

The major indications for LSCS in our study are 60 percent due to previous LSCS and 10\% due to breech and fetal distress. A study conducted in Karnataka by Unnikrishnan et al concluded that the major indications are placenta previa and malpresentation. ${ }^{10}$ In our study placenta previa constitutes $8 \%$ of the indications. This could be due to the sample size difference and the study period. A study done among the Tribal population in Gujarat by Desai et al shows that the major indications are previous LSCS (24\%), breech (16\%), and fetal distress $(31.2 \%) .{ }^{11}$ This indicates that the indications for LSCS throughout India are more or less the same irrespective of geographical settings.

The prevalence of NICU admission in our study after LSCS is $27 \%$. A study conducted by Roy et al among 217 mothers who underwent LSCS conclude that the prevalence of NICU admission was $15.2 \% .^{12}$ This difference may be due to a difference in the nature of the hospital (whether it is a secondary care unit or tertiary care unit) where the study has been conducted. This difference suggests further research in different settings.

In our study, the major indications for NICU admission for babies after LSCS is respiratory distress syndrome (46\%), and low birth weight (30\%). A study conducted by Panda et al among the tribal population in Delhi, concludes that the major indications are pre-maturity $(23 \%)$, and birth asphyxia (19\%). ${ }^{13}$ A study conducted by Shrestha et al in Nepal shows that the major indication is pre-term babies $(53 \%) .{ }^{14}$ These differences suggest that the indications vary with different settings and need further research.

A systematic review done by Gedefaw et al with 23 crosssectional studies done in Ethiopia, shows that the prevalence of neonatal sepsis of babies after LSCS was $19.15 \% .^{15}$ our study shows a much lower prevalence of $2 \%$. this could be due to the strict aseptic precaution protocol followed by the hospital, which needs further community-based research.

\section{Limitation}

This study has been done with adequate sample size and in medical college institutions and tertiary care hospitals, thus it reflects the high-quality tertiary maternal and child health care (MCH care) in Tamil Nadu. Since it is a hospital-based study the prevalence cannot be generalized to the whole population due to different rates of admission in different hospitals. Mothers with previous classical CS and mothers who are associated with other medical complications were excluded from the study which may influence the outcome of the pregnancy.

\section{CONCLUSION}

The indication of previous LSCS for LSCS among pregnant mothers is in a rising trend which needs holistic commitment to reduce the prevalence of LSCS. The major indications for NICU admissions are respiratory distress syndrome and low birth weight. The factors associated with NICU admission of babies after LSCS are a number of the previous history of abortions and the nature of LSCS (Elective or emergency).

\section{Recommendations}

Since the major indication for LSCS is previous LSCS, it is time to reconsider the patient's willingness for elective LSCS without medical indications. The approach of vaginal birth after caesarean (VBAC) delivery can be motivated among pre-LSCS mothers who have no complications for the same.

Funding: No funding sources

Conflict of interest: None declared

Ethical approval: The study was approved by the Institutional Ethics Committee

\section{REFERENCES}

1. Yoshioka-Maeda K, Ota E, Ganchimeg T, Kuroda M, Mori R. Caesarean section by maternal age group among singleton deliveries and primiparous Japanese women: a secondary analysis of the WHO Global Survey on Maternal and Perinatal Health. BMC Pregnancy Childbirth. 2016;16:39.

2. Neuman M, Alcock G, Azad K, Kuddus A, Osrin D, More NS et al. Prevalence and determinants of caesarean section in private and public health facilities in underserved South Asian communities: crosssectional analysis of data from Bangladesh, India and Nepal. BMJ Open. 2014;4(12):e005982.

3. Ronsmans C, Graham WJ. Maternal mortality: who, when, where, and why. Lancet. 2006;368(9542):1189-200.

4. Niino Y. The increasing cesarean rate globally and what we can do about it. Bio Sci Trends. 2011;5(4):139-50.

5. WHO Statement on Cesarean Section Rates. World Health Organization. 2015. Available at: http://apps.who.int/iris/bitstream/handle/10665/1614 42/WHO_RHR_15.02_eng.pdf;jsessionid=21FB1CB 6264FD221E6598A5F2C32FE2B? sequence $=1$.

Accessed on 2021 Aug 11.

6. The National Family Health Survey (NFHS-4). International Institute For population Sciences. 2015. 
Available at: http://rchiips.org/nfhs/pdf/NFHS4/ India.pdf. Accessed on 2021 Aug 11.

7. State Fact Sheet-Tamil Nadu. International Institute For population Sciences; 2015. Available at: http://rchiips.org/nfhs/pdf/NFHS4/TN_FactSheet.pdf . Accessed on 2021 Aug 11.

8. Seal S, Kamilya G, Mukherji J, Bhattacharyya S, De A, Hazra A. Outcome in Second- versus First Stage Cesarean Delivery in a Teaching Institution in Eastern India. Amer J Perinatol. 2010;27(06):507-12.

9. Singal S, Bharti R, Dewan R, Divya, Dabral A, Batra A et al. Clinical Outcome of Postplacental Copper T 380A Insertion in Women Delivering by Caesarean Section. J Clin Diagn Res. 2014;8(9):OC01-4.

10. Unnikrishnan B, B R, Aishwarya A, Nithin K, Thapar $\mathrm{R}$, Mithra $\mathrm{P}$ et al. Trends and Indications for Caesarean Section in a tertiary care Obstetric Hospital in Coastal South India. Aus Med J. 2010;1:3.

11. Desai G, Anand A, Modi D, Shah S, Shah K, Shah A et al. Rates, indications, and outcomes of caesarean section deliveries: A comparison of tribal and nontribal women in Gujarat, India. PLOS ONE. 2017;12(12):e0189260.
12. Roy KK, Baruah J, Kumar S, Deorari AK, Sharma JB, Karmakar D. Cesarean section for suspected fetal distress, continuous fetal heart monitoring and decision to delivery time. Indian $\mathbf{J}$ Pediatr. 2008;75(12):1249-52.

13. Panda PK, Panda PK. Clinical profile and outcome of newborns admitted to a secondary-level neonatal intensive care unit in tribal region of Odisha. J Clin Neonatol. 2019;8(3):155.

14. Shrestha $\mathrm{S}$, Karki U. Indications of admission and outcome in a newly established neonatal intensive care unit in a developing country (Nepal). Nepal Med Coll J. 2012;14(1):64-7.

15. Gedefaw G, Demis A, Alemnew B, Wondmieneh A, Getie A, Waltengus F. Prevalence, indications, and outcomes of caesarean section deliveries in Ethiopia: a systematic review and meta-analysis. Patient Safety Surg. 2020;14(1):11.

Cite this article as: Jeyamani B, Sowmiya B. Post cesarean pregnancy and its outcome. Int J Reprod Contracept Obstet Gynecol 2021;10:4397-401. 